\title{
Clarifying our Ideas in Persuasion Dialogue
}

\author{
GÁBOR FORRAI
}

Department of Philosophy and History of Science

Budapest University of Technology and Economics

Egry József St. 1. Bldg. E 610

1111 Budapest, Hungary

forrai.gabor@filozofia.bme.hu

\begin{abstract}
Persuasion dialogue sometimes helps us to clarify our ideas; this paper attempts to find out what this kind of clarification consists in. After examining Walton's analysis of the maieutic function of persuasion dialogue it concludes that it offers little help in understanding the phenomenon in question and proposes that clarifying our ideas consists in replacing narrowly individuated views with ones which improve the coherence of one's views and retain elements of the earlier views. It also argues that the clarification of our ideas so conceived is not one of the main goals of persuasion dialogue but rather an accidental even if welcome side effect.
\end{abstract}

Résumé: Le dialogue de persuasion nous aide parfois à clarifier nos idées. On tente de découvrir ce qu'est ce genre de clarification. Après avoir examiné l'analyse de Walton de la fonction maïeutique du dialogue de persuasion, on conclut qu'elle offre peu d'aide pour comprendre le phénomène en question. On propose que la clarification de nos idées consiste à remplacer des vues étroitement individualisées par celles qui améliorent la cohérence de vues et qui conservent des éléments des vues antérieures. On soutient également que la clarification de nos idées ainsi conçue n'est pas l'un des principaux objectifs du dialogue de persuasion, mais plutôt un effet secondaire accidentel, même si bienvenu.

Keywords: changing views, clarification, critical discussion, maieutic function, persuasion dialogue, pragma-dialectics, Walton

The kind of dialogue which has been most discussed in argumentation studies is the one in which the parties produce arguments to convince one another and thus settle their disagreements. Theorists coined various concepts to capture its essential characteristics, among which Walton's "persuasion dialogue" and the pragma-dialecticians" "critical discussion" (van Eemeren and Grootendorst 2004) are the best known. I am going to use Walton's term because Walton has a lot to say on issues related to the ones I will be exploring. I apply this term merely to identify a particular type of argumentative exchange without necessarily endorsing everything Walton says about it. 
When Walton first characterized persuasion dialogue, he did it in terms of its initial situation, main goal and the aim of the participants: persuasion dialogue starts from a conflict between points of views, its main goal is to resolve the conflict, and each participant seeks to persuade his partner, i.e. to resolve the conflict in favor of his own view (1989, pp. 5-6). Given this characterization a persuasion dialogue which does not settle the differences is simply a failure: neither the main goal nor the individual aim of one of the participants is reached. Nevertheless, it has surely happened to the reader that he took part in such a "failed" discussion, yet he did not experience it as a failure, but found it most enjoyable and stimulating; he felt he had learned something from the discussion, and now he understands much better both what the issue is and what he had in mind all along. This kind of experience is routinely described in terms of the extended metaphor of clarity. We say things like the issue came into sharper focus, we have gained a clearer view of the matter, we have grasped the essence of the argument, we can now express the point more precisely, etc.

Walton has always been keenly aware of this phenomenon and even came to modify the characterization of persuasion dialogue accordingly: now he says that the main goal of persuasion dialogue is to resolve or clarify the issue (2007a, p. 23). Indeed, one of the reasons why he distinguishes his notion of persuasion dialogue from the pragma-dialectic notion of critical discussion is that the latter, on his view, does not take into consideration "that many real dialogs seem to be quite successful even though the original conflict of opinions was not resolved" (2007a, p. 28). However, well-known as the phenomenon is, it seems that no one apart from Walton has devoted much attention to it. In this paper I will be exploring one aspect of this complex phenomenon, namely the clarification of our own ideas, which, as it will turn out, is not the same aspect Walton is primarily interested in. In particular, I want to explain what happens when our ideas are clarified and say something about how this is connected to the goals of persuasion dialogue.

In section 1 I will offer an initial characterization of clarifying our ideas and distinguish it from other things which also come under the heading "clarification". In Section 2 I will consider if Walton's account sheds light on clarifying our ideas and conclude that it does not. The point is not to criticize that account but to generate ideas: seeing why Walton's account does not capture the phenomenon I am interested in helps us to understand what is going on. Relying on the lessons drawn from this inquiry, in Section 3 I develop my own account through analyzing a concrete example. I will suggest that getting clear 
about our ideas consists in adopting new views which increase the coherence of our set of views but also preserve elements of our earlier views. In Section $4 \mathrm{I}$ am going to propose that no matter how much we treasure clarifying our ideas, this is not a main goal of persuasion dialogue.

\section{Clarification vs. clarifying our ideas}

"Clarification" is a term applied to a diverse group of phenomena and I will only be interested in one member of the group, which I will call "clarifying our ideas" while reserving "clarification" without a qualifier for the more inclusive concept. So let me start by demarcating the phenomenon which is the target of the following analysis first by describing what we experience when we manage to clarify our ideas and then by distinguishing it from some other kinds of clarification.

Imagine that you are participating in a persuasion dialogue and your partner raises questions and objections which are genuinely challenging, so you have to think or even think hard to answer them. This may happen because you had not been thinking on the issue long enough or because your partner is very smart or both. What really matters is that you have to come up with a novel response. It is not like when a student raises an objection to the view under discussion which you can identify as one of the standard objections and you can simply rehearse one of the standard responses you know very well from the literature. So you cudgel your brain and hit upon what seems to you a good response. Nevertheless, you do not feel that giving that response involves abandoning the position you had put forward. You may think that you have only found a better way to express the same idea, i.e. you are making the same point but this time more astutely. Or that your conceptual grasp has improved: you have finally got a firm grip on the idea, and now you really understand what it involves. Another option is to think that it is the idea itself which was perfected: it took on a more definite shape, its contours became sharper, some minor and insignificant detail was corrected, the rough edges were smoothed out. No matter how you choose to describe the change, it seems to you that it is definitely an improvement. The merits of your view are now more conspicuously displayed. Had you presented it the way you can present it now, your partner would have found it more cogent. If he still doesn't find it cogent, he can at least see much better the target he wants to shoot at. Nevertheless, the gist of your position has not changed. This increase in comprehensibility and cogency is more like improving one's looks by make-up 


\section{Gábor Forrai}

than by cosmetic surgery; the former does not alter the face but merely directs the attention to the attractive features.

The idiom "clarifying our ideas" is indeed quite suitable for capturing the central features of this experience. It expresses that it is an improvement which does not affect the identity of the ideas concerned: they are the same as before, their essence has not been touched. It also has connotations of increased visibility, transparency, lack of barriers. There are other expressions we may use to describe what happens when we have this sort of experience-we may speak of refining, elaborating, articulating, working out or developing our ideas-, and sometimes they indicate more precisely what happens, but it is "clarifying our ideas" which we most frequently use.

Before contrasting it with other kinds of clarification I need to add two remarks. First, clarifying our ideas may happen outside a dialogical setting. It does not even require a virtual dialogue with imaginary opponents. You may think of a philosopher who is in the process of developing her novel ideas. She sees the direction she is going but only vaguely. She is sitting in front of her computer typing, reading in every couple of minutes what she has written, and erasing it, because the text just does not feel right, it does not express what she is after. Then finally there it is: that is what she has meant. Even though she may be regarded as playing two roles, that of the proponent and the critic, this is not even a virtual dialogue, since the critic is limited to saying "not good enough" and "good enough", and does not raise specific question or give reasons for her dissatisfaction.

Second, clarifying our ideas in an actual dialogue has distinctive advantages. Imagine our philosopher again but this time not in front of a computer but conversing with a colleague. When she makes an attempt to lay out her ideas the colleague will not merely say "not good enough" but asks questions, raises objections, points out ambiguities, etc. The utterances act as pointers, so her search for the best way of putting her ideas has the character of a guided search whereas her solo effort was closer to random search. This makes clarifying our ideas in dialogue more efficient than thinking alone.

In addition to efficiency, the level of clarity achieved in actual dialogue is often higher, because our ideas must face a stricter tribunal than in cases in which we judge them alone. Our partner may point out tensions, ambiguities, missing steps and further implications we have not been aware of. Ideas which must meet stricter requirements are likely to be more articulate. This is why the clarification of our ideas achieved in persuasion dialogue often comes as a pleasant surprise. We enter the discussion convinced that our ideas are perfectly clear, but at the 
end of the discussion we find that they are clearer than before, and that we have learned something about our position which we did not expect to learn.

As I said, clarifying our ideas is just one type of clarification. When we say that a discussion made things clearer we may be referring to several things, and we usually do not distinguish them. The reason why we do not is that they often happen together. The two other kinds of clarification which regularly accompany clarifying our ideas is getting clear about our opponent's position and getting clear about the nature of our disagreement. At the beginning of the debate we may not see how the various claims our opponent advances hang together, what exactly his arguments are supposed to support, but as we argue back and forth at least some of the things our opponent says start to fit together in an intelligible way. We also may not discern the central points of disagreements right away. This happens when there are several claims in dispute and in the beginning we do not see how these are related; it is as if the points of disagreement constituted an unstructured list. In the course of the discussion we come to perceive that some items on the list are merely the consequences of the others, which is an important realization because by focussing on these fundamental points of disagreements we have a better chance to make progress.

It is easy to see why these two kinds of clarification frequently accompany clarifying our ideas. Let us consider the clarification of our opponent's position first. One thing which may make you wonder what your opponent has in mind is when he rejects the conclusion of your argument while accepting your premises. Then you might wonder: it is it because you are making use of an assumption he rejects? Or is it because there is some hidden ambiguity in one of your premises and he does not understand it in the way you do? If you explain your opponent's apparent lack of comprehension by answering one of these questions affirmatively, you do not only learn something about his view, but your own view also becomes clearer: you become aware of an assumption you did not know about or come to distinguish between two slightly different views, the difference between which eluded you so far. So finding out about your opponent's position and your own position may be two sides of the same coin. This example may also be invoked to illustrate how clarifying the points of disagreements may render your own ideas clearer, but here is another example. In arguing about various claims it may turn out that their fate depends on whether you accept or reject one particular claim, which thus turns out to be a central point of disagreement. This discovery about the connections between the various disputed claims is by the same 


\section{Gábor Forrai}

token a discovery about the structure of your position. What seemed to you an undistinguished part of your position emerges from the discussion as something fundamental. Alternatively, if you and your partner argue about a point at length but neither of you of sees the need to connect it to other points of disagreement that may signify that it is separate issue, which is both an insight about the nature of your differences and about the shape of your own position.

Even though attempts at sorting out the opponent's position and the structure of the disagreement very often give rise to reflections about one's own position and result in the clarification of one's ideas, the latter is not only conceptually distinct from the other two kinds of clarification but may also occur independently. Take, for instance, a situation in which you are debating some issue you are intimately familiar with with someone who is a novice in the field. He does not know how the various points are normally stated, how the usual arguments go, how the various threads are distinguished, what depends on what, etc. whereas you all know that. It is highly probable then that you have to make an effort to find out what your partner thinks and where your disagreements lie, but it is highly unlikely that your own ideas get clearer. As for the opposite case in which your ideas are clarified without the other two kinds of clarification taking place you may think of an asymmetric debate, in which your partner does not seek to defend a position but is merely concerned with raising doubts about yours.

Finally I would like to consider two other phenomena which come under the heading "clarification" but are farther away. "Clarifying the issues" sometimes stands for resolving the disagreement or making progress towards that: we learn that one side was right about these points, the other side about those, the rest is still controversial. Clarification in this sense is genuine success, but it is not intimately connected to clarifying our ideas. We may clarify the issues without our ideas being clarified, and the other way round. It is worth noting that the plural first person is applied differently in the two cases. When we manage to clarify the issues in the sense of persuading one another, that is a joint achievement; it takes two to settle the disagreement, you cannot do it alone. When we clarify our ideas that normally means that both of us do that: you clarify your ideas and I clarify mine. (An exception is when we have roughly the same view and engage in dialogue to work it out, e.g. when co-authors of a paper consider how to cope with some criticism. In this case, however, we do not have a persuasion dialogue, even though it may include episodes which may be regarded as such.) 
Even farther away lies clarification as a speech act directed at one's earlier speech act with the purpose of clearing away the obstacles in the way of continuing the conversation. If I say something that my partner finds obscure so she cannot respond, she asks for clarification, and if I give one, she will know how to go on. This kind of clarification sometimes goes together with clarifying our ideas. The reason why my partner finds what I said obscure may be that I did not have clear ideas, and I can only perform the speech act of clarification successfully if I get clear about what I wanted to say. Nevertheless, the speech act of clarification rarely requires the clarification of our ideas because the need for clarification usually arises from more mundane reasons like careless formulation or failure to pay attention to the partner's background knowledge or idiolect. Notice that the speech of clarification is not intimately connected to persuasion dialogue. Sure enough, we may ask for clarification in persuasion dialogue, but we may do so in all kinds of dialogue. ${ }^{1}$

There are certainly other phenomena which may be called clarification and one may also give a more principled taxonomy, but I trust the foregoing discussion suffices to separate the one I intend to discuss.

\section{Walton on the maieutic function of persuasion dialogue}

As early as his second book on argumentation Walton remarks that

[I]n many familiar arguments we begin and end with the same set of statements, perhaps feeling that the argument really "hasn't gone anywhere". Yet if we think of it, such arguments are often curiously revealing in that they more clearly articulate or make us aware of our own and our dialogue-partner's deeply held commitments not brought out until the argument took place. (1984, p. 248)

It does not seem implausible that in writing this he is concerned with two kinds of clarification discussed in the previous section, clarifying our ideas and clarifying our partner's position. Let us then see what we can learn from his account.

The book is his first attempt to explore the use of formal dialogue games for argumentation theory, and the games pro-

\footnotetext{
${ }^{1}$ For an analysis of the speech act of clarification see (Walton 2007b). Walton obviously regards this kind of clarification independent of his work on maieutic function of persuasion dialogue to be discussed in the following section, for he does not even mention the latter in this paper.
} 
posed are defined in the by now familiar fashion: ${ }^{2}$ there are locution rules specifying the permissible locutions (e.g. assertions, questions, challenges); structural rules describing under what conditions the various moves are appropriate (e.g. a question "Why S" can be answered by denying commitment to S or by producing an argument for $\mathrm{S}$ ), commitment rules specifying how the various locutions affect the content of the participants' commitment stores (e.g. denying commitment to $p$ removes $p$ from one's commitment store), and win-loss rules expressing the participants' objectives.

The phenomenon of coming to understand our own position better is analyzed through the formal dialogue game CBV, which features two kinds of commitment stores for each participant: a light-side commitment store for commitments actually expressed and a dark-side commitment store. The dark-side commitment store is a repository for a definite set of propositions just as the former, except that the speaker does not know what propositions it contains. The way dark-side commitments come to light is captured by the following commitment rule:

If a player states "No commitment S" and S is in the dark side of his commitment store, then $\mathrm{S}$ is immediately transferred into the light side of his commitment store. (1984, p. 250)

This rule serves to preclude inconsistent commitments. It works in this way: if you seek to deny commitment to a proposition which you are implicitly committed to, you cannot do that; all you achieve is that your commitment now becomes public, so your opponent can go ahead and use it in arguing against you.

The rule gives a clear picture of how it happens that our ideas get clearer in the debate. Your opponent puts forward an argument which you can only fend off by denying one of its premises. However, when you are just about to deny commitment to the premise - to move "No commitment S"-, you realize that you are committed to it. It is like your opponent were a doctor trying to feel the point where it hurts, and if he finds it, you will know that.

We can also see why Walton mentions becoming aware of our own commitments and those of our partner's at the same breath. It is essentially the same process: you become aware of your commitment by moving the proposition in question from the dark-side to the light-side commitment store and your part-

\footnotetext{
${ }^{2}$ I use the terminology of the later and more widely read book written together with Erik Krabbe (1995).
} 
ner becomes aware of it in exactly the same way. So we are really talking about joint discovery of commitments.

The idea receives a more elaborate treatment in a later book co-authored with Erik Krabbe (1995). The account offered there is similar in its broad outlines but differs in the details. It begins with noting that persuasion dialogue may have a maieutic function, which consists in articulating, clarifying or eliciting our deeper commitments (1995, pp. 35-36). The maieutic function is fulfilled when critical questioning by the opponent makes one come forward and actually say what he is committed to. The previous rule is mentioned briefly as a possible descriptive rule expressing the idea that we sometimes identify our commitments in catching ourselves in the act of denying them (1995, p. 146), but is not part of, as it were, the official account.

We have a more detailed and slightly different characterization of the dark-side commitment store: it is a repository for propositions which have not been expressed rather than which are unknown to the participant in question. The reason for this change is that Walton and Krabbe make a more qualified statement about our ignorance of the propositions there, namely that we are in general or often ignorant of them (1995, pp. 11-12, $125,134){ }^{3}$ There is an additional idea which was at best hinted at earlier, namely that dark-side commitments are deep or fundamental $(1995$, pp. 11, 56, 169) in the sense that they really matter for the participants; abandoning them would amount to changing one's basic character (1995, pp. 139-140).

We also have a more sophisticated dialogue game called permissive persuasive dialogue (PPD), which is aimed to model a looser type of dialogue, in which getting clear about the opponent's position is an important issue, and the stress is more on the underlying ideas than the exact wording. The way we should treat the propositions belonging to the dark-side commitment store is regulated by a commitment rule and two structural rules. The former is that they cannot be retracted (1995, pp. 149-150). One's commitment to them may change - they may be moved to the light-side commitment store-, but one cannot abandon them; the purpose of this rule is to capture that these commitments are deep. The first structural rule prescribes that whenever we have a proposition in the dark-side store, and the opponent asks if we are committed to it, we should concede it. It is by obeying this rule that dark-side commitments are transformed

\footnotetext{
${ }^{3}$ One might wonder how one may incur commitment to a proposition one is not aware of, but this is not much of a problem. The dark-side commitments do not sit still, they are manifested in the inferences one draws from them (Walton and Krabbe 1995, p. 125). If one puts forward an argument, he is liable for the hidden assumptions the argument presupposes.
} 
into overt concessions. The way this may unfold in actual dialogues is that our argument makes the opponent suspect that we may be committed to some proposition, so he asks if we are. It is this question which makes us realize that we have been committed to the proposition all along. The second structural rule declares that once a proposition has been moved from the darkside store to the light-side store, the move to renounce commitment to it becomes unavailable. This again reflects the deep or fundamental character of these commitments.

To see how this apparatus works let us take a look at Walton's and Krabbe's examples. The first example is the following:

George is a committed Socialist but frustrated by the continual postal strikes, he argues that the post office should be taken over by private enterprise. His friend Bob replies: "How can you say that, George? After all, you are a Socialist, and Socialists do not think that the state functions should be run by private enterprise." (1995, p. 35)

The other example occurs in an extended discussion concerning the issue whether it is right to allow a fatally ill baby to be born so that his organs can be made available for transplantation surgery. At one point Bruce, who would allow the baby to be born, argues that the baby would have a very poor quality of life anyway, and is rapidly confronted by his opponent saying that his previous arguments relied on the importance of saving life, so he cannot say now that the baby's life does not matter (1995, pp. 90, 145-6). In keeping with the rules of PPD both George and Bruce should concede and thereby make their commitments explicit. (Bruce indeed does, the George example is not developed.)

What should we make of this account? It certainly covers some cases of clarifying our ideas, but on reflection it seems that it does that by accident rather than by design. There are two reasons for this evaluation. The less important one is its focus on deep commitments, which we cannot abandon without changing our character. Clarifying our ideas does not have to involve such deep commitments. It does generally involve some degree of commitment, i.e. the ideas we clarify are typically ones we cherish, since if an idea does not matter to us, we rarely take the trouble to make it clear. It is much easier to surrender an idea we do not care about than to clarify it. ${ }^{4}$ We might still think that

\footnotetext{
${ }^{4}$ I feel uneasy about dark-side commitments being both deep and generally unknown. It seems to me that we are normally aware of the commitments
} 
Walton is just overstating the case, and we can improve his account by purging it of the features securing the depth of the commitments in question, i.e. the commitment rule forbidding retraction of dark-side commitments and the structural rule which forbids renouncing a light-side commitment to a proposition which used to be in the dark-side commitment store.

But there is also a more important reason deriving from the core of the account. The maieutic function of persuasion dialogue is fulfilled by moving a proposition from the dark-side to the light-side commitment store. In the new account the former commitment store is defined as the place for propositions which have not been expressed, and even if we are usually ignorant of these propositions, ignorance is not what distinguishes between the contents of the two commitment stores. So take a proposition you consciously endorse and can also formulate very precisely any time but which you have not expressed so far in the current dialogue, either because you believe it is part of the general knowledge you share with your partner, or because you regard your partner as sufficiently familiar with your way of thinking. The proposition still figures in your arguments, you just do not say it. It is then in your dark-side commitment store. It turns out, however, that your assessment of your partner's knowledge was wrong, but as your arguments tacitly invoke the proposition in question, your partner starts to suspect that you may be committed to it. So he goes "Aren't you assuming that...", and you respond "Sure I do". The maieutic function is certainly fulfilled in this instance, but the crucial element of clarifying one's ideas is missing: there has been no improvement. Your ideas have not been refined, your conceptual grasp has not become more solid, and you have not found a better way to make the point; so none of the expressions we use to describe the clarification of ideas applies. Making the implicit explicit suffices for fulfilling the maieutic function, but it does not suffice for clarifying our ideas. Walton and Krabbe's account is designed to capture an important phenomenon which belongs in the field of dialectics, but the dialectical perspective does not capture the distinctive feature of the clarification of ideas. This point complements one made in the previous section, that clarification may also take place outside a dialogical context. Putting them together we can draw the conclusion that a dialectical account can specify neither sufficient, nor necessary conditions for the clarification of ideas.

which truly matter to us; for instance, one does not need to be challenged in a debate to figure out if one is a theist or an atheist. 
Nevertheless, this does not mean that the account is completely irrelevant for our purposes. Remember that Walton and Krabbe would regard the case just described as untypical, since they also hold that dark-side commitments are generally unknown. In the typical instances the implicit commitment we make explicit is one we did not know of. Becoming able to say something which was part of our position but which we were not aware of certainly counts as clarifying our ideas. This suggests that the episodes which can be characterized in terms of the maieutic function and the ones which can be characterized in terms of the clarification of ideas in persuasion dialogue largely overlap, so even if Walton and Krabbe are primarily interested in a dialogical phenomenon, their account may also be viewed as saying something about the clarification of ideas. And what it says is this: clarifying our ideas consists in finding out about our implicit commitments we did not know of and formulating them explicitly.

Seeing what is wrong with this account derived from Walton and Krabbe's analysis will bring us closer to understanding what is going on. Let us have a closer look at their examples. The first thing to note is that the examples do not fit the theoretical description very well, because the commitments in question do not seem genuinely dark-side commitments. Consider George. His partner, Bob, takes his commitment to Socialism for granted, which suggests that it has been openly acknowledged, possibly in an earlier conversation. It is also unlikely that one can be a dedicated Socialist and regarded by his friends as such without knowing it. It may well be true that George did not announce his Socialism in this particular conversation, and this may be a reason for taking it to belong to the dark-side commitment store, but the notion of dark-side commitment store was not meant to contain items belonging to our common knowledge. The maieutic function is not realized in saying something which is common knowledge but in making one's commitment common knowledge by saying it. Remember, the reason why Walton is interested in the maieutic function is that it explains how persuasion dialogue can be instructive even if the issues are not decided. The Bruce example is even more straightforward. Not only has Bruce based his previous arguments on the importance of saving lives, he has actually said: "This baby [referring to the fatally ill baby] is one life to be considered, but other lives are involved. We must have respect for all life." (1995, p. 87) So respect for human life, having been actually declared earlier in the conversation, cannot be a darkside commitment. 
The second thing to notice is that the examples can still be understood as cases of the clarification of ideas. Commenting on the George case Walton and Krabbe explain that George has two options: withdrawing his support for the privatization of postal services or "refining" or "modifying" his commitment to Socialism. Whichever he chooses, his commitment, which was "vague and general", "is put into a more consistent and specific form" (1995, pp. 35-36, cf. 56). The most plausible way of understanding this is that, being a Socialist, George has always disapproved of private enterprise, albeit in a vague and unspecific way, and Bob's argument forces him to become more specific, and reject privatization tout court or propose a concrete qualification, both of which would count as clarification.

The Bruce example can be interpreted in a similar fashion, even though Walton and Krabbe do not provide us with clues here. When warned that he cannot both sustain the argument from the respect for life and the argument from the poor quality of life the baby would have, Bruce may come to realize the distinction between life as such, life in the medical sense and life replete with characteristically human experiences, a genuinely human life. He may either opt for the former and drop the argument from the quality of life, or admit that the life worthy of respect is the genuinely human life and drop the first argument or reinterpret it in a way that it reduces to the second one. Construed in this way, his opponent's warning makes him appreciate the ambiguity of his initial commitment, eliminate the ambiguity, and adjust his arguments to his now unambiguous position.

Putting these observations together shows that clarifying our ideas does not consist in becoming aware of an implicit commitment and making it explicit. The examples as construed above qualify as clarifications of ideas, but the explication of what was originally unknown does not happen, for the ideas in question were not unknown in the first place.

Reflecting on the example, however, also shows why the picture derived from the Walton-Krabbe account is tempting. Consider George again. Pressured by Bob, he either announces that he opposes each and every form of privatization or that he opposes privatization except in special cases which he goes on to characterize in some detail. He has not formulated either stances before, so we have a new explicit commitment. But this new explicit commitment surely does not appear all of a sudden as if George had an unexpected change of heart, since he was against privatization prior to explicitly committing himself to the strict or to the qualified opposition. So it may seem plausible to say that what transpired was that he has become conscious of an implicit commitment and has made it explicit. 
The way to resist this tempting picture is to see that the explicit commitment George accepts in response to Bob's objection is not quite the same as his earlier commitment. The earlier commitment was unspecific: it was a general opposition to privatization, whereas the new commitment is specific: it is strict opposition to privatization or opposition qualified in some particular way. This leads to an important point: commitments can be individuated broadly and narrowly. If we individuate broadly, the unspecific, the strict and the qualified opposition to privatization is the same commitment. If we individuate in a finegrained fashion, they are different. (The same point can be made in connection with the other example as well. Respect for life in the medical sense, respect for genuinely human life, and respect for life ambiguous between these two are the same commitment if we individuate broadly, but they are not the same if we individuate narrowly.) Let us see what difference this point makes.

If we tell George's story individuating broadly, we must say that his commitments have not changed. Then it is entirely false that he was not aware of this commitment, and it is rather dubious that it was implicit. Most importantly, a central element of the clarification of ideas is absent, which is that the clarified ideas are in some sense superior to the yet unclarified ideas. Indeed, broad individuation makes the improvement puzzling: if George's commitments have not changed, how can they have become better? If we tell the story individuating narrowly, then George's commitments have changed. Therefore it is misleading to say that he had not been aware of his commitment before Bob put pressure on him. He knew very well that he did not like privatization. He did not know then that he opposes privatization in a specific (strict or qualified) way, but that was not ignorance, since before Bob asked his question he was not committed to either specific anti-privatization stance. It is also false that Bob's question prodded him to make his commitment explicit, since the commitment made explicit is different from the earlier commitment. Telling the story in this way we leave room for the central element of clarifying our ideas which was necessarily absent on the broad individuation: since George assumes a new commitment, his position may indeed become better (in a sense yet to be explained).

We may now sum up what we have learned from the scrutiny of Walton's and Krabbe's theory. We have first seen that a dialectical theory is ill-suited to capture the clarification of ideas, which is not an essentially dialectical phenomenon but one which is merely facilitated by a dialogical context. Reflecting on what the theory might still be saying on our question lead to a second conclusion, namely that we should be mindful of broad 
and narrow individuation, and only narrow individuation allows us to express the improvement clarifying our ideas involves.

\section{Clarifying our ideas and increasing coherence}

The previous scrutiny of Walton and Krabbe's account gives us good starting-points. First, the account should not be developed in terms of commitment, for commitment presupposes a dialogical setting, and clarifying our ideas is not an intrinsically dialogical phenomenon. Belief is better, because it is a private attitude, but it will not do for our purposes. One does not have to actually believe something to get clear about it. One may discuss something in order to find out whether one should believe it; possibly, one may even defend something one disbelieves in order to find out if there is anything going for it. So we need a more inclusive concept. I shall be talking about views, and I propose to understand having a view as accepting some proposition at least temporarily for the purpose of inquiry. To have a view is then to have at least a minimal pro-attitude towards a proposition. A view may be a fully-fledged belief, but it may involve a much weaker kind of acceptance which does not suffice to guide one's actions and which may be renounced any time. Second, we should individuate views in a narrow or fine-grained fashion, because this allows us to explain the clarification of ideas as a change in views.

Of course, not all changes of fine-grained views amount to clarification of ideas. If my opponent convinces me that I am wrong and he is right, my narrowly individuated views change but do not get clarified. We have, as it were, merely identified the genus proximum under which our target belongs, and now we must look for the differentia specifica. So what is special in this change?

Let us start with an example, an excerpt from a debate conducted on the internet in which one of the participants' views become clearer (Hanson 2014). The issue is the following: the pretty, the smart and the healthy enjoy all kinds of privileges, but that is fine with us; on the other hand, we are upset by inequalities based on parental wealth, ethnicity, race, gender, sexual orientation or dominant culture. Is there a reason behind the difference?

IMASBA: $[\ldots]$ Also the inequalities we do not care about as much are smaller in magnitude (and limited) and their distribution is less unequal. In the area of beauty the 99th percentile doesn't have much on the 95th percentile 
compared to the difference between those percentiles in the area of financial wealth. There are also limits to how beautiful one can be, while one can keep accumulating money exponentially.

Ken Arromdee: There are limits to how male or white you can be and those still count as privileges.

IMASBA: White privilege comes from the use of money and coalition connections, not from the color of the skin itself. There's no inherent advantage to it (like there is with increased intelligence, strength or health) [...]

Ken Arromdee: The exact same thing you're saying for white skin is also true of being good-looking. There's no inherent advantage to it like there is for intelligence. Beauty privilege comes from the fact that people who are good-looking have greater access to money and connections.

And while you can argue there's an instinctive aversion to ugly people, there's also an instinctive aversion to members of an outgroup, making white privilege really quite similar.

IMASBA: The instinctual aversion to members of an "out-group" is/was really not that strong in a forager society, least of all if the out-group is based on ethnicity. In fact even early agrarian societies didn't care much for ethnicity. Does that make taking advantage of your good looks more fair? No, but it does make it far harder to suppress, and guess what, our society indeed has unfavorable ideas about people who use their looks to get things.

Let us examine closer how IMASBA's views evolve under Ken Aromdee's criticism. I present them in a more straightforward, reconstructed form and ignore two aspects of her position - the magnitude and uneven distribution of properties underlying unacceptable inequalities - and focus on the part which comes under attack, the idea of limits. The problem the blog raises is this:

(P) We are only justified in regarding some inequalities as harmful and others as relatively harmless if there is some difference between the two.

In the beginning IMASBA is concerned only or primarily with one harmful inequality, the inequality of wealth, which she contrasts with the harmless inequalities of brains and looks. So her initial views include: 
(I1) We care less about inequalities of looks and brains.

(I2) We care much about inequalities of wealth.

Given (P), he must find some important difference between the properties in (I1) and (I2), so she suggests (1):

(1) We care less about inequalities deriving from properties whose magnitude is limited.

Objection (O1) forces her to switch from (1) to (2).

(O1) We care much about inequalities of race and sex (O1a), but the magnitude of those properties is also limited (O1b). [contradicting (1)]

(2) We care less about inequalities deriving from inherently advantageous properties whose magnitude is limited.

Then objection (O2) makes her abandon (2) to in favor of (3)

(O2) Looks are not inherently advantageous. [contradicting the conjunction of (I1) and (2)]

(3) We care less about inequalities from deriving properties whose magnitude is limited if they are either inherently advantageous or the advantage they bring through their effect on others is harder to suppress.

What happens from the dialectical point of view is that IMASBA concedes her opponent's point and changes her view in a way which renders the point harmless. I want to draw attention to two features of the transition.

First, the later views retain a central element of the earlier ones, the idea of limits. If we seek to express the central element in propositional form we get something very vague and unspecific, like this:

(C) Regarding certain inequalities harmful and others as harmless has something to do with the fact that some of the latter rest on differences which are limited.

(1), (2) and (3) are different ways of making (C) more specific.

In order to bring out the second feature, let us forget about the dialectical perspective and focus on the complete sets of views IBASMA endorses at the various stages of discussion. 


$$
\begin{aligned}
& \mathrm{I} 1, \mathrm{I} 2, \mathrm{P}, 1 \\
& \mathrm{I} 1, \mathrm{I} 2, \mathrm{P}, 2, \mathrm{O} 1 \mathrm{a}, \mathrm{O} 1 \mathrm{~b}
\end{aligned}
$$

$$
\mathrm{I} 1, \mathrm{I} 2, \mathrm{P}, 3, \mathrm{O} 1 \mathrm{a}, \mathrm{O} 1 \mathrm{~b}, \mathrm{O} 2
$$

initial position

first objection

answered

second objection

answered

Not only is (S3) larger than the previous sets, it is a better constellation of views than either (S1) or (S2). (S1) is consistent, but only accounts for our differential attitude to brains and looks on the one hand and wealth on the other. The explanatory principle (1) does not generalize to other cases such as inequalities based on sex and race. So we have a choice between resting content with a limited account or replacing (1) with something else. The latter is certainly preferable. (S2) is such an attempt. It offers explanation for our attitude to sex- and race-based inequalities (O1a) in terms of a new explanatory hypothesis (2) and the relevant facts about sex and gender $(\mathrm{O} 1 \mathrm{~b})$, which is all to the good. However, (2) does no longer fit the relevant facts about beauty $(\mathrm{O} 2)$, so (S2) is not fully successful. The gain in scope is counterbalanced by a loss in consistency. We would certainly prefer a set of views having the scope of (S2) but shedding its problems. (S3) is a set of views of this kind.

A natural way to spell out this improvement is provided by the coherentist theories of justification. ${ }^{5}$ Coherentist theories maintain that the primarily locus of justification is a system of views rather than individual views, and individual views are justified in virtue of belonging to a sufficiently comprehensive and coherent system. Coherence is a compound property consisting of features like consistency, inferential connectedness, explanatory power, and tight integration. Consistency includes logical, probabilistic and decision-theoretic consistency. Inferential connectedness stands for the presence of inferential connections among the views: the more inferential connections there are and the stronger they are, the more coherent the system is. Inferential connections which provide explanations are especially valuable. Tight integration means that there are not many views which stand more or less alone and are not connected to the rest of the system, i.e. there are few exceptions, special cases, unexplained anomalies. The tighter a set of views is integrat-

\footnotetext{
${ }^{5}$ Analyzing the clarification of ideas in coherentist terms does not commit us to the claim that coherentism is the right theory of justification or even to the claim it is the right sort of epistemological theory for explaining justification through argumentation (even though I happen to endorse the latter (Forrai 2014)).
} 
ed, the more coherent it is. Comprehensiveness is necessary to make sure that coherence is not bought cheap: it is easy to preserve coherence by excluding views threatening it, e.g. by rejecting anomalous experimental findings. ${ }^{6}$

Judged from a coherentist point of view (S1) is coherent: the demand for an explanation of our differing attitudes in terms of relevant differences in the inequalities is satisfied. However, its coherence is due to its lack of comprehensiveness, the failure to take into account other inequalities. (S2) is more comprehensive but less coherent. Its explanatory principle (2) is contradicted by the case of inequality of beauty, so it is inconsistent as it stands. The inconsistency can be removed by adding the qualification to (2) that it does not apply to beauty, but that would diminish the tightness of integration, since beauty would now become an exception which is not accounted for. (S3) outperforms (S1) by its comprehensiveness and (S2) by its coherence.

I suggest that the features just pointed out supply the differentia specifica we were looking for. Clarifying one's ideas is to be analyzed as changing one's narrowly individuated views in a way that both makes one's set of views more coherent and also retain central elements of one's earlier views.

This analysis helps to explain why it is natural to describe what we experience in terms of clarity. On the one hand, our views have changed. On the other hand, our current views are fairly similar to the earlier ones. If we individuate them broadly, in terms of their conceptual components rather than in terms of their truth conditions, we will regard our current views identical to the earlier ones, since they share central elements. While participating in a debate we are actually inclined to individuate broadly, which is manifested in the fact we are rarely explicit about changing our views. Consider IMASBA again. She does not say: "I was wrong in saying that the inequalities we care less about derive from properties whose magnitude is limited. The view I now propose is that the inequalities we care less about derive from inherently advantageous properties whose magnitude is limited." She shifts from (1) to (2) without commenting on the shift; indeed she presents her new view as if it were a defense or explanation of the earlier one. This kind of behavior is fairly typical, especially if the objections are answered without much delay as in face-to-face discussion or in a discussion on the internet. ${ }^{7}$ Indeed, it is intimately connected to the way we

\footnotetext{
${ }^{6}$ This is a fairly generic description of coherentism, not a particular version. It relies on ideas taken from Sellars (1963), Harman (1973) and BonJour (1985).

${ }^{7}$ It is probably rooted in the confrontational character of debate; we are sensitive to the shifts in our opponents' point of view, because we can have a
} 
think of the identity of the debate. We are out to persuade someone of the truth of a particular claim. The reason why we believe that we are still conducting the same debate is that it is the same claim we want our partner to accept. It is the constancy of our agenda which defines the identity of the debate for us, and the broad individuation of views assures constancy of agenda.

However, as already noted in the previous section, adopting broad individuation for our views leads to something of a puzzle, because we also feel that the view now clarified is superior in some way. How could our later views be superior if they are identical to the earlier ones? We resolve the tension by invoking clarity: our views are the same as before, but now they are clearer. To put it differently, the tendency to broad individuation hides improvement, i.e. the increase in coherence, and the idiom of "clarity" offers a way to express that our views have improved.

Natural as it is to use this idiom, it ultimately rests on a confusion. The narrow view we arrive at by the end of the discussion is more specific than the broad view of which our initial and final view are both instances, so it is perfectly legitimate to describe it as "clearer". (Compare (C) and (3) in the analysis of the debate.) What is wrong is to describe our views as "becoming clearer", because that is comparing apples and oranges. The broad view does not become clearer because it does not change. The narrow views change, but they change not in terms of specificity, but in terms of increasing coherence. (Compare (1) and (3).) The idiom of "clarity" fuses the temporal change of increasing coherence and atemporal relation of higher specificity (Fig. 1.) $)^{8}$

good shot only if we see the target clearly. Being sensitive to shifts in our own position does not offer much advantage. This behavior has its practical use because it shortens the discussion. At the same time, it makes it difficult to track which claim is defeated or vindicated. It might even qualify as a violation of Rule 14 of pragma-dialectics (van Eemereen and Grootendorst 2014, pp. 154-155), which demands that refuted standpoints should be retracted.

${ }^{8}$ This explanation resembles Hume's explanation of our belief in the continuous and independent existence of physical objects (Hume 1975). Hume claims that we have a natural tendency to mistakenly identify different but closely associated impressions like seeing someone and hearing her voice. At the same time, we remain aware of the difference - sight and sound do differ. So we resolve the contradiction - identical things do not differ - by postulating an independent and continuous object which our impressions are impressions of. In the present case we have a natural tendency to identify our initial position and final position and eliminate the tension by introducing the pseudo-process of clarification. 


\begin{tabular}{|c|c|c|}
\hline \multicolumn{2}{|c|}{ broad view } & atemporal \\
\hline initial narrow & final narrow view & more specific \\
\hline
\end{tabular}

Figure 1.

\section{Is it a main goal of persuasion dialogue to clarify our ideas?}

In this final section I will examine how tight the connection is between persuasion dialogue and clarifying our ideas as it was analyzed in the previous section. I am going to argue that it is rather loose. True as it is that persuasion dialogue sometimes makes our ideas clear and we sometimes engage in this type of dialogue primarily in the hope of attaining that, this is not a main goal. It may be a goal of the individual participants as winning the debate is, but it is not a main goal of the activity itself in the sense in which the resolution of disagreement is. I have two reasons to offer.

To start with the first one we should notice that "main goal" is very much like function in the biological sense. First, biological functions are connected to purposes or aims without presupposing a subject having these purposes or aims: the function of the heart is to pump blood, even if there is not anyone who wants blood to be pumped. Similarly, in talking about the main goals of persuasion dialogue we do not assume that any participant has these goals. Two people may engage in persuasion dialogue with the sole purpose of impressing the audience, but the goal of the dialogue itself is something different. Second, biological function allows failure: a bad heart does not pump blood, but its function is still to pump blood. Similarly, a persuasion dialogue still serves its main goals even if these are not achieved. Indeed, having a function is compatible with massive failure. Protective coloration fools few predators, yet it is its function to do that.

Function in the biological sense is nowadays usually explained in selectionist terms as the cause of reproduction (Millikan 1984). The idea is roughly this: 
an item $i$ of type $I$ has the function to $f$, if it is a reproduction of earlier items of type $I$ and $i$ was produced because the earlier items of type $I \operatorname{did} f$.

For example, the function of the reader's heart is to pump blood, because it is a reproduction of earlier hearts, and the reader's heart was produced because the earlier hearts did pump blood. Notice that the reproduction does not have to be a biological process: the function of a copy of a logic textbook is to help students learn logic for the reason that it was reprinted because earlier copies did help students learn logic.

If we understand the main goals of persuasion dialogue as its functions, our question becomes this: do we keep engaging in persuasion dialogue again and again partly because earlier persuasion dialogues helped to clarify our views? Or, to put it differently, is the practice of persuasion dialogue maintained in part because it sometimes leads to the clarification of ideas? Given the earlier analysis of making our ideas clear as changing views in such a way that

(a) central elements of earlier views are preserved and

(b) the new set of views is more coherent,

this seems very implausible for two reasons.

First, if clarifying our ideas is indeed a function of persuasion dialogue, the practice of persuasion dialogue is maintained because it brings about the conjunction of these features.

I grant for the sake of argument that the improved coherence it sometimes brings is one of the reasons why we keep engaging in persuasion dialogue. Does increasing coherence coupled with retaining earlier ideas provide a stronger reason? It does not. Having more coherent views has obvious benefits: more coherent views are more likely to be true, and believing the truth is more likely to make our life better. But the benefits of more coherent views do not depend on whether these views are based on elements of our earlier views or radical innovations. Having good views is a good thing in itself, and having good views resting on elements of earlier views is no better. So even if improving coherence is a function of persuasion dialogue, clarifying our ideas is not.

Another way of making this point starts from the idea that improving coherence is only accidentally connected to retaining earlier views. We happen to be better at tinkering with earlier ideas than at fashioning brand new ones, this is just how our mind works. As a result of this, in improving our own ideas we often build upon earlier ideas. Now here is a logical point: if the 
realization of a function $F$ is accompanied by a feature $E$, that does not render the conjunction of $F$ and $E$ a function. Think of the heart again. Pumping blood is its function. In addition to pumping blood, the heart also emits rhythmic noises, but that does not make noisy pumping a function of the heart. Similarly, if improving coherence is a function of persuasion dialogue, and improving coherence is normally achieved by preserving something of our earlier views, that does not make the conjunction of improvement and preservation, i.e. the clarification of ideas a function.

There is another argument to support the same reason. Let us assume that the previous argument fails, and more coherent views building on earlier ideas are preferable to more coherent views which are brand new. Then it is indeed a good thing to have a practice for clarifying our ideas. Nevertheless, this alone would not make clarifying our ideas a main goal: in addition, there should be some mechanism through which the success in clarifying our ideas effects the continuation of the practice. I do not think such a mechanism exists, because persuasion dialogue is more widespread than persuasion dialogue resulting in the clarification of ideas. The point is not that, as a matter of fact, most persuasion dialogues fail to bring clarity. Having a function does not imply that the function is normally fulfilled or even that it is fulfilled in the majority of cases.

The point is rather that the clarification of ideas pertains only to certain kinds of persuasion dialogues, namely those motivated by intellectual curiosity and not by practical interest. When we argue about such matters as which party to vote for, why Peter left Mary, whether a politician accused of embezzlement will be put behind bars, whether this is the right time to invest into real estate, how the president of the university is likely to react to students' protests etc. clarification of ideas does not happen. And if it did, we would not care: it would be a strange thing to say that even if we did not agree who to vote for, we had a terrific discussion and now I understand much better why I am going to cast my vote this way. Making our ideas clear is confined to scientific ventures and relaxed intellectual conversation about matters somewhat removed from everyday concerns. Since it is exhibited only by a special kind of persuasion dialogue, clarifying our ideas cannot be what keeps the much broader type of persuasion dialogue up and running. So bringing clarity might perhaps be a function of a special kind of persuasion dialogue, but it cannot be the function of persuasion dialogue as such. 
The second reason is that the normative structure of persuasion dialogue is not designed and cannot be redesigned to promote the clarification of ideas. If I may invoke a biological analogy once again, a good way to figure out the function of an organ is to observe its anatomy. If it is structured in a way that makes it suitable to produce a certain effect, then the effect is a good candidate to be its function. The "anatomy" of persuasion dialogue does not suggest that that clarification is one of its functions.

To see this consider first our best accounts of persuasion dialogue. Most accounts we have are normative in character: they spell out how we should conduct such dialogues, what moves are permissible and at what points, etc. The most influential account of that kind is probably the pragma-dialectic theory of critical discussion (van Eemeren and Grootendorst 2004). Critical discussion is construed as an ideal procedure for resolving disagreements. It is not inconceivable a priori that the ideal procedure for resolving disagreement is also an ideal or at least a suitable procedure for clarifying our ideas, but looking at the details reveals that it is not. Clarifying our ideas is a particular way of changing our views, and pragma-dialectics has nothing to say on how our views should be modified; its rules merely tell us when a standpoint must be abandoned, when it can be maintained, and the only rule about changing views is that one cannot abandon a standpoint in favor of another one without announcing that one has withdrawn the earlier standpoint and is setting out a new one. Walton and Krabbe's formal dialogue games are equally intended as ideal models (1995, pp. 174-177), which can be used to evaluate actual practices, and they equally fall short in this respect: they tell us how commitments are established, when they can be retained or should be retracted, but do not advise us on modifying them.

One may respond to this observation by pointing out that there is a good theoretical reason why our current models do not address the issue of changing one's views. If one gives up his original position and adopts a new one, we have two debates rather than one. If one gives up his initial standpoint, the debate is thereby closed: the disagreement has been resolved. ${ }^{9}$ If he adopts a new standpoint, we have a different disagreement, which is the starting point for a new debate. Since our models are concerned with what happens within debates and not with

\footnotetext{
${ }^{9}$ Strictly speaking, this is only true in asymmetrical discussions, in which the opponent does not have a standpoint of his own. In a symmetrical debate one may give up her original standpoint without accepting that of her opponent; but the debate is closed even in this case, since the original disagreement is replaced with a new one.
} 
the reasons why we initiate new debates, it cannot be held against them they do not address the issue of clarifying our ideas. However, conceding this point leaves the observation intact. In so far as our current models are largely correct accounts of the normative structure of persuasion dialogue, persuasion dialogue does not serve to promote the clarification of ideas.

Another way to counter the observation is to say that what it really shows is that our current models of the normative structure of persuasion dialogue are inadequate: we could provide a better set of norms for our argumentative practices, and the better norms would be conducive to clarifying our ideas. I do not think there is much hope for a normative model which would both serve the resolution of disagreement and the clarification of ideas. One reason has already been mentioned. The normative models we have are dialectical: they perceive argumentation as taking place in the social sphere, so they deal in public standpoints and social commitments. Clarifying our ideas may or may not take place in the social sphere; this is why I formulated my account in terms of views rather than commitments.

There is also a second and even more pressing reason: it is very difficult to conceive how current rules of persuasion dialogue could be modified in a such a way that the dialogue should be conducive to the clarification of ideas, i.e. improvement of coherence coupled with building on earlier views.

Here is an example. We could have a rule constraining what objections can be raised: in addition to being valid and proceeding from premises conceded by one's partner, they should force the partner to respond by putting forward a standpoint which retains important elements of the earlier standpoint. Such a rule would certainly promote making our ideas clear, since the partner would then only have two options: to clarify or to yield. But such a rule cannot be obeyed. One's partner can always respond by replacing his earlier standpoint with a new one rather than improving the earlier standpoint. There is no way to raise an objection that rules out this possibility.

Alternatively, we could propose a rule constraining the responses to objections, like this: valid objections based on accepted premises can only be answered by putting forward an improved standpoint preserving the central ideas of the earlier one. This rule would support improving clarity by ruling out non-clarifying responses. But that rule would tie one's hand in a most unfair fashion. Why could you not replace the earlier standpoint with a brand new one which would do equally good service to your overall position? Indeed, this rule is undesirable because it bars the participants from exploring the issue in depth and from putting forward all considerations which are relevant. 
So even if one could construct rules for a type of dialogue which serves the clarification of ideas and the settlement of disagreement at the same time, it is hard to see why one would be willing to participate in a dialogue of that type.

Let me sum up the main conclusions. Clarifying one's ideas consists in changing one's views in such a way that the new views are more coherent and preserve central elements of the earlier views. Clarifying our ideas in this sense is not a main goal of persuasion dialogue; it does sometimes happen, but persuasion dialogue is not designed to promote this.

Acknowledgements: The research leading to this paper was supported by the Hungarian Scientific Research Foundation, grant no. 109456. I am grateful to Gábor Zemplén and Zsófia

Zvolenszky for their comments on an earlier version and to Gábor Forgács, Ákos Gyarmathy, Tihamér Margitay, János Tanács for useful discussion.

\section{References}

BonJour, L. (1985). The Structure of Empirical Knowledge. Cambridge, Mass.: Harvard University Press.

Eemeren, F.H. van and R. Grootendorst (2004). A Systematic Theory of Argumentation. The pragma-dialectical approach. Cambridge: Cambridge University Press.

Forrai, G. (2014). Argumentation without Arguments Proper. In Ten Years of Facebook, The Third Argumentor Conference, eds. G. Horváth, R. K. Bakos, É. Bíró-Kaszás, 219-238. Oradea/Debrecen: Partium Press, Debrecen University Press.

Hanson, R. (2014) Pretty Smart Healthy Privilege. http://www.overcomingbias.com/2014/09/pretty-smarthealthy-privilege.html. Accessed 2 December 2015.

Harman, G. (1973). Thought. Princeton: Princeton University Press.

Hume, D. (1975). A Treatise of Human Nature, edited by L. A. Selby-Bigge, 2nd ed. revised by P. H. Nidditch, Oxford: Clarendon Press, 1975.

Millikan, R.G. (1984). Language, Thought and Other Biological Categories. Cambridge, Mass: MIT Press.

Sellars, W. (1963). Science, Perception and Reality. London and New York: Routledge \& Kegan Paul and The Humanities Press.

Walton, D.N. (1984). Logical Dialogue-Games and Fallacies. Lanham, Maryland: University Press of America. 
Walton, D.N. (1989). Informal Logic. A Handbook for Critical Argumentation. Cambridge: Cambridge University Press.

Walton, D.N. (2007). Dialog Theory for Critical Argumentation. Amsterdam: John Benjamins Publishers.

Walton, D. N. (2007b). The Speech Act of Clarification in a Dialogue Model. Studies in Communication Sciences 7, 127159.

Walton, D. N. and E. C. W. Krabbe. (1995). Commitment in Dialogue. Basic Concepts of Interpersonal Reasoning. Albany: State University of New York Press. 